\title{
MAPA ESTRATÉGICO PARA UMA INDÚSTRIA DO SETOR LÁCTEO
}

\section{1- Silvana Anita Walter*}

Doutora em Administração pelo Programa de Pós-Graduação em Administração da Pontifícia Universidade Católica do Paraná (PUC-PR), Brasil.

Professora do Programa de Pós-Graduação em Administração da Universidade Regional de Blumenau (FURB), Brasil. silvanaanita.walter@gmail.com

http://lattes.cnpq.br/6055446867536139

\section{2- Rosane Maria Simon Vedovatto}

Mestranda em Administração pela Universidade Nacional de Missiones (UNAM), Brasil.

romariasimon@hotmail.com

http://lattes.cnpq.br/7336476885058435

\section{3- Tatiana Marceda Bach}

Mestranda em Administração pelo Programa de Pós-Graduação em Administração da Universidade Regional de Blumenau (FURB).

tatibach@gmail.com

http://lattes.cnpq.br/7161413668995622 


\section{MAPA ESTRATÉGICO PARA UMA INDÚSTRIA DO SETOR LÁCTEO}

\section{RESUMO}

Este estudo objetivou desenvolver, a partir das perspectivas tradicionais do Balanced Scorecard e da do meio ambiente, um mapa estratégico para uma indústria do setor lácteo. Desenvolveu-se uma pesquisa descritiva com estudo de caso e coleta de dados por meio de entrevistas, documentos, observação participante e questionário. Para análise dos dados, empregou-se, com o auxílio do Atlas.ti 5.0, a análise documental e de conteúdo do tipo temática. As análises permitiram observar que a empresa possui como desafio ampliar a captação de matéria-prima e melhorar o sistema de informação; que realiza parcerias em produtos e em pesquisa; e que procura inovar em equipamentos e produtos, além de ser pioneira no Brasil no tocante à produção de soro concentrado de leite. Como implicação gerencial, destaca-se a criação do mapa estratégico. A inclusão da perspectiva do meio ambiente e a proposição de medidas para empresas do setor lácteo se caracterizam como contribuição teórica.

\section{Palavras-chave}

Ferramenta estratégica, Balanced Scorecard, Mapa estratégico, Perspectiva do Meio Ambiente, Empresa de Lácteo.

\section{STRATEGIC MAP FOR A DAIRY COMPANY}

\section{ABSTRACT}

This study aimed to develop, from the traditional perspectives of the Balanced Scorecard and from the environment, a strategic map for an industry in the dairy sector. It was developed a descriptive research with case study and data collection through interviews, documents, participant observation and questionnaire. For data analysis, it was used, with the aid of Atlas.ti 5.0, the documental and content analysis of the thematic type. The analysis had pointed out that the company has as a challenge to expand the collection of raw materials and improve the information system; which carries partnerships in products and in research; and seeks to innovate in equipment and products, besides being a pioneer in Brazil in terms of concentrated milk whey production. As a managerial implication, it is emphasized the creation of the strategic map. The inclusion of the environment perspective and the proposition of measures for companies in the dairy sector are characterized as a theoretical contribution.

\section{Keywords}

Strategic tool, Balanced Scorecard, Strategic Map, Perspective of the Environment, Dairy Company. 


\section{Introdução ${ }^{1}$}

Atualmente, os executivos vêm percebendo a necessidade de conhecerem mais indicadores dos aspectos do desempenho organizacional, além do financeiro, pois estes são imprescindíveis para manter a excelência empresarial. Neste sentido, Kaplan e Norton (1997) apontam o Balanced Scorecard (BSC) como uma ferramenta muito útil para a verificação de outros indicadores. Essa ferramenta propicia a mensuração do desempenho organizacional sob quatro perspectivas que compreendem os indicadores da excelência organizacional: financeira; clientes; processos internos da empresa; e aprendizado e crescimento. Com isso, as empresas têm a possibilidade de, ao mesmo tempo, acompanharem o desempenho financeiro, o progresso na construção de capacidades a na aquisição dos ativos intangíveis necessários para o crescimento (Kaplan \& Norton, 1997).

Atualmente, o nível de utilização da ferramenta do BSC em organizações é significativo, tal como confirmado por vários estudos, dentre os quais o realizado por Maisel (1999 apud Kaplan \& Norton, 1999) com 1910 empresas americanas, indicando que 43\% destas declaravam utilizar o BSC; o de Bain e Company (1999 apud Kaplan \& Norton, 1999) que relatou que 55\% das empresas americanas pesquisadas e $45 \%$ das européias afirmavam utilizar o BSC. Em relação ao Brasil, o estudo de Fontes (2004) destacou que, das 500 maiores empresas brasileiras, $57,1 \%$ implantaram o BSC como sistema e método de avaliação econômico-financeira e $64 \%$ enfatizaram a utilização do BSC nessa função.

Apesar dessa ampla utilização apontada pelos estudos mencionados, outras pesquisas demonstram que as organizações encontraram dificuldades e obstáculos na implantação e no uso do BSC ou, até mesmo, fracassaram na tentativa de aplicar o método, conforme apontam Pessanha (2004); Soares Júnior e Prochnik (2004); Goldszmidt e Profeta (2004); Carvalho, Dias e Prochnik (2005); Beber, Ribeiro e Kliemann Neto (2006); Prieto et al. (2006), dentre outros.

Kaplan e Norton (1997) consideram que as quatro perspectivas do BSC são úteis para diversas empresas, mas que, em determinados contextos, para se chegar ao sucesso de uma estratégia, há necessidade da ampliar uma ou mais perspectivas. Neste sentido, compreende-se que, para desenvolver um mapa estratégico para uma organização do setor de lácteos, torna-se fundamental considerar uma quinta perspectiva - a do meio ambiente -, haja vista a existência de leis e de normas que governam a responsabilidade ambiental das mesmas, bem como a cobrança do mercado diante da ampla possibilidade de essas empresas causarem impactos ambientais.

Diante do apresentado, o problema de pesquisa deste estudo pode ser apresentado por meio da seguinte pergunta: Qual a configuração de um mapa estratégico, a partir da ferramenta BSC, de uma organização do setor de lácteos? Quanto ao objetivo, este ficou assim definido: desenvolver um mapa estratégico para uma empresa do setor de lácteos a partir de diferentes perspectivas do BSC.

\section{Balanced Scorecard}

O BSC consiste em uma ferramenta estratégica empregada pelas organizações para, por meio de um conjunto de medidas de desempenho, representar sua visão e estratégia (Kaplan \& Norton, 1997). Os autores consideram que os objetivos e as medidas do BSC surgem da visão e da estratégia da empresa e também de um processo hierárquico (top-down), os quais traduzem a missão e a estratégia de uma unidade de negócios em objetivos e em medidas tangíveis. Esta ferramenta está embasada em quatro perspectivas de desempenho organizacional que formam a estrutura da mesma: financeira; clientes; processos internos da empresa; e aprendizado e crescimento.

Os objetivos financeiros são o foco para as medidas das outras perspectivas, pois qualquer que seja a medida, esta deverá aumentar o desempenho financeiro da empresa. Esses objetivos devem desempenhar dois papéis na empresa: definir o desempenho financeiro esperado da estratégia e servir de meta principal para os objetivos e medidas de todas as outras perspectivas do BSC (Kaplan \& Norton, 1997). Os autores apontam três temas financeiros que norteiam a estratégia empresarial: crescimento e mix de receita; redução de custo/melhoria de produtividade; e utilização dos ativos/estratégia de investimentos.

Quanto à perspectiva dos clientes, segundo Kaplan e Norton (1997), é por meio dela que as empresas identificam os segmentos de clientes e de mercado com os quais pretendem competir. Assim, as empresas podem alinhar as medidas essenciais de resultados aos segmentos de mercado e aos clientes com os quais pretendem atuar. Nesta perspectiva, as empresas geralmente se utilizam de dois conjuntos 
de medidas: genéricas ou essenciais (participação de mercado, retenção dos clientes, captação de clientes, satisfação dos clientes e lucratividade de clientes) e desempenho dos resultados fornecidos aos clientes (atributos dos produtos/serviços, relacionamento com o cliente e imagem e reputação).

$\mathrm{Na}$ perspectiva dos processos internos, Kaplan e Norton (1997) apontam que os executivos identificam os processos considerados como os mais críticos para a realização dos objetivos dos clientes e acionistas. Para os autores, o BSC, nessa perspectiva, requer que os executivos tenham definida a cadeia de valor completa, iniciando nos processos de inovação, seguindo pelas operações e finalizando nos serviços de pós-venda.

Na perspectiva de aprendizado e crescimento, encontra-se a infraestrutura para atingir as perspectivas financeiras, dos clientes e internas, pois os objetivos desta perspectiva indicarão o capital humano, isto é, os colaboradores a serem focados, capacitados e motivados em busca dos resultados das três perspectivas anteriores. Kaplan e Norton (1997) apontam que, nesta perspectiva, existem três categorias principais: capacidade dos funcionários; capacidade dos sistemas de informação; e motivação, empowerment e alinhamento.

Discutido o BSC e suas quatro perspectivas básicas, na próxima seção, ainda referente à base teórico-empírica, apresenta-se a perspectiva do meio ambiente que se incluiu no BSC, visto que, no decorrer da pesquisa, esta emergiu como um importante fator para a estratégia da organização pesquisada.

\section{A perspectiva do meio ambiente no setor de lácteos}

As exigências no tocante às leis ambientais vêm se intensificando no setor de lácteos, o que amplia a importância de as indústrias se comprometerem com os cuidados relacionados ao meio ambiente. Neste sentido, destaca-se a Resolução no 313, de 29 de outubro de 2002, do Conselho Nacional do Meio Ambiente (CONAMA), que dispõe sobre o Inventário Nacional de Resíduos Sólidos Industriais. Essa resolução se constitui de um conjunto de informações sobre a geração, as características, o armazenamento, o transporte, o tratamento, a reutilização, a reciclagem, a recuperação e a disposição final dos resíduos sólidos gerados pelas indústrias do país (Brasil, 2002).

Também se destaca a Resolução 054/06, da Secretaria de Estado de Meio Ambiente e Recursos Hídricos do Estado do Paraná (SEMA), de 22 de dezembro de 2006, que, em âmbito estadual, rege o controle da qualidade do ar (Paraná, 2006).

Outra lei a ser destacada é a Portaria 001, de 9 de janeiro de 2008, da Secretaria de Estado de Meio Ambiente e Recursos Hídricos do Estado do Paraná (SEMA)/Instituto Ambiental do Paraná (IAP), que regulamenta as informações que a empresa deve passar ao órgão estadual sobre as suas atividades no que se refere à emissão de gases ambientais (Paraná, 2008).

Já a Portaria 019, de 10 de fevereiro de 2006, do mesmo instituto, "consiste no controle e acompanhamento periódico, por parte da atividade poluidora, dos sistemas de tratamento de efluentes líquidos em operação, através de coleta, medição e análise do efluente final". Essa portaria destaca que as empresas deverão apresentar ao IAP a declaração dos seus resíduos de efluentes de acordo com sua vazão e em uma periodicidade que varia em função da gravidade desses efluentes.

Por sua vez, o Sistema Estadual de Reposição Florestal Obrigatória (SERFLOR), por meio da Resolução 028, de 17 de agosto de 1998, da Secretaria de Estado de Meio Ambiente e Recursos Hídricos, determina a obrigatoriedade de "todos os consumidores de matéria prima de origem florestal efetuarem a reposição florestal em quantidade equivalente ao volume consumido" (Paraná, 1998).

A Lei no 10.165, de 27 de dezembro de 2000, do Instituto Brasileiro do Meio Ambiente e dos Recursos Naturais Renováveis, institui uma taxa a ser cobrada de acordo com o porte da empresa e os relatórios realizados pela mesma, bem como os órgãos competentes para essa fiscalização e cobrança (Brasil, 2000$).$

Além das leis ambientais, o mercado pressiona as organizações do setor de lácteos para que tomem cuidados com o meio ambiente. Neste contexto, Sousa e Bertolin (2008) desenvolveram um estudo sobre a responsabilidade ambiental em uma empresa do setor de lacticínios a fim de analisar como as representações sociais dos gestores moldam a aprendizagem organizacional no que concerne ao aspecto ambiental na organização. Para tanto, os autores verificaram como alguns aspectos, como uma Estação de 
Tratamento de Efluentes (ETE) e a presença ou ausência de discussões de caráter ambiental na realidade organizacional, influenciam a construção das representações sociais de meio ambiente e, consequentemente, a efetividade da aprendizagem organizacional.

O mercado, segundo Sousa e Bertolin (2008), exerce pressão sobre as empresas de lácteos no que tange à questão ambiental. Com isso, os gestores dessas empresas passam a compreender o fator ambiental como uma oportunidade de mercado, ou seja, passam a usá-lo como forma de marketing. Os autores destacam, ainda, que a responsabilidade ambiental em uma empresa auxilia, por meio da diminuição dos desperdícios, na redução de custos, bem como colabora para uma educação ambiental dos seus funcionários (Sousa \& Bertolin, 2008).

Assim, observa-se que a responsabilidade ambiental é importante para as empresas do setor de lácteos, porque, além de atender às normas vigentes, permite responder à pressão do mercado e reduzir desperdícios.

Como contribuição teórica para este estudo, sugere-se, a partir do destacado por Maganha (2006), algumas medidas da perspectiva do meio ambiente que podem ser adotadas por empresas do setor quando empregarem o BSC:

a) consumo de água: a água é o recurso natural mais empregado no setor e se destaca, porque sua utilização está relacionada à garantia das condições sanitárias e de higiene. Esse recurso é empregado em operações de limpeza, lavagem da massa láctea, bem como no resfriamento e geração de vapor. Ressalta-se que o maior consumo de água ocorre em operações secundárias, como as de limpeza, de desinfecção e de resfriamento;

b) geração de resíduos: os resíduos gerados pelo setor de lácteos podem ser: restos de produtos, restos de embalagens, lodo da estação de tratamento de efluentes, resíduos de material de manutenção, resíduos das áreas administrativas, resíduos perigosos (óleos, baterias) e geração de efluentes líquidos. A descarga de efluentes industriais pode ser considerada como o principal impacto ambiental do setor. Neste sentido, destaca-se a quantidade de efluentes gerados e a qualidade destes resíduos. Normalmente, os pontos de geração de efluentes industriais são: lavagem e limpeza de produtos remanescentes; derramamentos, vazamentos, operações deficientes de equipamentos e transbordamento de tanques; perdas no processo, tais como em operações de "partida" e de "parada" do pasteurizador e extravaso dos produtos, arraste de produtos na evaporação e aquelas resultantes do acerto das condicionadoras; e, descarte de produtos, tais como: soro ou leite ácido;

c) consumo de energia: está associado à garantia de qualidade dos produtos, principalmente daqueles submetidos a tratamento térmico, a refrigeração e a armazenamento. Os tipos de energia mais empregados são o térmico (vapor e água quente) e o elétrico (refrigeração, iluminação, ventilação e outras operações que empregam equipamentos elétricos). O consumo de energia depende do tipo de produto preparado e de outros fatores relacionados à idade da instalação, ao grau de automação, à tecnologia usada, às operações de limpeza, a medidas adotadas de economia de energia, entre outras;

e) emissões atmosféricas: os equipamentos utilizados nas operações de lácteos podem gerar emissões atmosféricas, como gases resultantes da queima de combustível (monóxido de carbono (CO), óxidos de nitrogênio (NOX) e de enxofre (SOX) e material particulado); vazamentos de gases refrigerantes ou de vapor; exaustão de ar quente do evaporador de leite; esterilização das folhas de alumínio com peróxido de hidrogênio, em máquinas Tetra Pak; odores; e vapores da(s) torre(s) de resfriamento. A esse respeito, se frisa que tanto a implantação de programa de manutenção periódica de caldeiras quanto o monitoramento e controle das emissões dos gases de combustão auxiliam o funcionamento apropriado do sistema e proporcionam a otimização da combustão, reduzindo a emissão de poluentes;

f) ruído e/ou vibração: ruídos próprios do funcionamento da indústria, como os emitidos por diversos equipamentos, motores de bombas e tráfego de caminhões.

Como vantagem da inclusão da perspectiva do meio ambiente no BSC apontam-se os objetivos, as metas e os indicadores de desempenho ambiental integrados à visão da organização, o que faz com que a preocupação inerente à perspectiva do meio ambiente passe a ser parte integrante da visão estratégica das organizações, podendo ser relacionada com outras perspectivas e seus objetivos. 
No sentido apontado, a perspectiva do meio ambiente pode impactar diretamente na perspectiva financeira em virtude dos investimentos necessários e da redução/eliminação de multas e de custos de gerenciamento dos resíduos. Esta perspectiva também se relaciona com a perspectiva dos processos internos, visto que auxilia na eliminação dos desperdícios e na ampliação da produtividade. Tem-se, ainda, o impacto na perspectiva dos clientes no que tange à melhoria da imagem da empresa. Desta forma, é importante que a empresa divulgue a seus clientes, aos seus fornecedores e ao mercado no qual está inserida, os cuidados e o respeito que procura ter em relação ao meio ambiente, de modo que isso se torne um atrativo para indivíduos e organizações que procuram comercializar com empresas éticas e comprometidas com o meio ambiente. Além disso, tem-se consequências para a perspectiva de aprendizado e crescimento, haja vista a conscientização ambiental dos funcionários e o incremento na saúde e na segurança no trabalho.

Com relação às desvantagens, pode-se dizer que a principal ocorre no caso de empresas que tenham pressa em obter alguma certificação, pois essa perspectiva impacta em gerenciamento ambiental e excelência operacional, bem como em melhoria contínua, ou seja, em objetivos de longo prazo.

\section{Metodologia da Pesquisa}

Para atingir os objetivos propostos, realizou-se uma pesquisa de caráter descritivo empregando a técnica de estudo de caso. De acordo com Gil (1999), as pesquisas descritivas têm como objetivo a descrição das características de determinada população ou fenômeno ou, então, o estabelecimento de relações entre variáveis. De acordo com Yin (2005), os estudos de caso consistem em uma investigação empírica de um fenômeno em seu contexto, sobretudo quando os limites entre contexto e fenômeno não estão bem definidos. Na perspectiva de Stake (2005), o estudo de caso, enquanto forma de pesquisa, é definido pelo interesse por um caso individual, e não pelos métodos empregados. Quanto ao tipo de estudo de caso realizado, utilizou-se o estudo de caso único, ou seja, realizado em uma única organização (Yin, 2001).

O caso escolhido é o da empresa Concentrado Indústria de Produtos Lácteos Ltda., marca Sooro, localizada na região oeste do Paraná. Em 2001, o proprietário fundador arrendou uma unidade de concentração de um laticínio e, juntamente com sua sócia e esposa, iniciou as atividades da Sooro. Inicialmente, a indústria transformava o soro de leite descartado pelas indústrias de queijo em um produto diferencial no mercado brasileiro: o soro concentrado. Em 2005, a empresa atingiu o quádruplo de sua produção inicial, colocando no mercado 10.000 toneladas de sólidos. A Sooro atualmente possui um parque industrial de cerca de 3.996,99 $\mathrm{m}^{2}$ de área implantada e um quadro funcional de 120 colaboradores, além de realizar a comercialização de outros produtos: soro em pó e creme. Neste contexto, a escolha dessa empresa se deu por sua adequação aos objetivos deste estudo, visto que possuía apenas o Planejamento Estratégico tradicional, com foco na perspectiva financeira, e não havia realizado a implantação de um BSC.

No que tange à perspectiva temporal, destaca-se que esta pesquisa pode ser considerada como transversal. Com o intuito de garantir a confiabilidade do estudo, realizou-se a coleta de dados por meio de consulta a diferentes fontes, o que permitiu a triangulação dos dados. Dessa forma, empregaram-se entrevistas semiestruturadas, análise documental, observação participante e questionário semiestruturado.

Para a realização das entrevistas, que ocorreu em março e abril de 2009, utilizou-se um roteiro semiestruturado que continha questões relativas às cinco perspectivas a serem analisadas: financeira, clientes, processos internos, aprendizagem e crescimento, e ambiental. Assim, realizaram-se, com os principais dirigentes da organização pesquisada, sete entrevistas, sendo que cada uma teve a duração média de uma hora e meia e foram transcritas de forma literal para a realização das análises. Desse procedimento resultaram 107 páginas de transcrição.

Realizou-se a análise documental de outubro de 2008 a abril de 2009 por meio de consulta a documentos internos da organização pesquisada, como relatórios e o planejamento estratégico de 2009 , bem como consulta a leis ambientais. Buscou-se identificar, por meio desses documentos, informações importantes relacionadas às cinco perspectivas analisadas.

A observação participante ocorreu pela atuação de um dos pesquisadores como gerente de recursos humanos na empresa analisada no período de outubro de 2008 a abril de 2009. Descreveram-se os dados 
obtidos com a observação em diários de campo e se fez uso dos mesmos posteriormente para complementar a análise dos resultados obtidos.

Aplicou-se um questionário semiestruturado, em abril de 2009, com os mesmos indivíduos que participaram das entrevistas. Após a realização das entrevistas, solicitou-se a esses participantes que respondessem a um formulário com questões abertas indicando as principais variáveis que, na opinião deles, estavam relacionadas às cinco perspectivas analisadas.

Para análise dos dados, empregou-se a análise documental e a análise de conteúdo. A análise documental, segundo Godoy (1995, p. 21), refere-se ao “exame de materiais de natureza diversa, que ainda não receberam um tratamento analítico, ou que podem ser reexaminados, buscando-se novas e/ou interpretações complementares". Empregou-se este tipo de análise aos dados obtidos por meio das entrevistas, dos questionários e dos relatórios de observação. De acordo com Bardin (2002), a análise de conteúdo consiste em técnicas de análise de mensagens por meio de procedimentos objetivos e sistemáticos, podendo ser qualitativos ou quantitativos, os quais permitam inferência a respeito do conteúdo da mensagem. Na presente pesquisa, empregou-se o tema como unidade de registro, o qual consiste em uma unidade de significação de tamanho variado que é percebida naturalmente no texto analisado segundo critérios relativos à teoria que serve de guia à análise. Assim, a análise temática consiste em encontrar "núcleos de sentido" dentro da comunicação e cuja presença é importante para a análise que está sendo realizada (Bardin, 2002).

Realizou-se a análise de conteúdo com o auxílio do software Atlas.ti, versão 5.0, por meio da identificação das unidades de significação (e atribuição de um rótulo (código) inspirado na teoria de base para representar a idéia presente. De acordo com Bardin (2002), a codificação consiste na transformação dos dados brutos, o que, por meio de um recorte, permite atingir uma representação do conteúdo capaz de evidenciar para o pesquisador características presentes no material analisado. Dessa forma, codificaram-se todas as citações pertinentes ao objetivo da pesquisa. Posteriormente, objetivando-se a comparação entre as perspectivas analisadas, optou-se pela construção de famílias. Essas famílias, visualizadas por meio de um esquema gráfico de relações semânticas, se encontram aqui apresentadas em figuras. No decorrer de todo o processo, sempre que pertinente, realizou-se a criação de comentários e notas de análise com o objetivo de registrar informações que se consideram importantes para consulta futura. É o caso de comentários complementares, significados e síntese de resultados.

Após a identificação dos objetivos e da proposição dos indicadores, realizou-se um feedback para a diretoria da empresa no tocante aos resultados encontrados e ao mapa estratégico proposto. Esse feedback também objetivou a obtenção de aprovação e consenso pela empresa no tocante ao mapa formulado, que consiste em uma das etapas sugeridas por Kaplan e Norton (1997).

\section{Análise dos Dados}

Nesta seção, analisam-se os resultados obtidos na pesquisa, destacando os objetivos estratégicos da empresa para cada uma das cinco perspectivas, os indicadores propostos para a avaliação do alcance desses objetivos e o mapa estratégico com base no BSC.

Na Figura 1, apresentam-se os objetivos e os indicadores para a perspectiva financeira.

\begin{tabular}{|l|l|}
\hline Objetivos estratégicos & Indicadores \\
\hline Ampliar em $10 \%$ o faturamento por ano. & $\begin{array}{l}\text {-Faturamento mensal } \\
\text {-Lucratividade }\end{array}$ \\
\hline Ampliar o mix de produto. & $\begin{array}{l}\text {-Número de novos produtos oferecidos } \\
\text {-Receita gerada pelos novos produtos }\end{array}$ \\
\hline Reduzir de forma geral os custos em $8 \%$. & $\begin{array}{l}\text {-Redução dos custos com produção } \\
\text {-Redução dos custos com água potável }\end{array}$ \\
\hline
\end{tabular}

Figura 1: Objetivos estratégicos e seus indicadores para a perspectiva financeira

Observa-se que a Sooro possui um objetivo geral para essa perspectiva, destacado na Figura 1 em negrito, de ampliar em $\mathbf{1 0 \%}$ o faturamento por ano. Para mensurar a obtenção desse objetivo, sugere-se à empresa empregar os indicadores de faturamento mensal e de lucratividade. No que se refere a este objetivo maior, a empresa está investindo na estruturação de uma área comercial a partir da organização interna - cadastro de clientes, controles internos; criação, treinamento e integração da equipe de vendas; e 
pós-venda - o que possibilita à equipe de vendas ampliar sua área de atuação quanto aos produtos atuais, bem como, no futuro, colocar no mercado os novos produtos.

Para atingir esse objetivo de crescimento, a empresa está investindo para ampliar o mix de produtos. Esse investimento, num total de 12 milhões de reais, está sendo feito na construção de uma torre de secagem, o que possibilitará que a empresa se torne autossuficiente no processo de secagem de soro, além de viabilizar novos produtos que terão uma área maior de aceitação no mercado, como o soro desmineralizado, o concentrado protéico e, o mais inovador, a lactose concentrada. Como indicadores para esse objetivo, propõe-se: a) o número de novos produtos oferecidos e b) a receita gerada pelos novos produtos.

A aquisição de novos equipamentos e a melhoria dos processos de produção também auxiliarão na redução dos custos da empresa, que objetiva reduzir $\mathbf{8 \%}$ dos custos gerais. Dentre os investimentos em equipamentos, destaca-se a aquisição do Polischer, que tornará potável a água resultante do processo de produção, viabilizando, assim, sua reutilização e a diminuição da vazão no tratamento dos efluentes. Isto não só reduzirá os custos da empresa, como também representará um cuidado a mais com o meio ambiente. Outro fator que auxiliará na redução de custos da empresa é a exploração de toda a sua capacidade de produção. Porém, para isso, a empresa necessita ampliar, por meio do aumento do número de fornecedores, o volume de matéria-prima recebida, principalmente, no período de entressafra. Para a consecução desse objetivo, propõem-se, como indicadores, a redução dos custos com produção e a redução dos custos com água potável. Além disso, percebe-se que há ociosidade na fábrica durante entressafra. Neste sentido, a administração e as lideranças necessitam montar um planejamento para melhorar a captação da matéria-prima, pois isso implica diretamente na lucratividade da empresa, bem como no aumento das vendas, o que significa que a empresa necessitará produzir mais.

Os objetivos estratégicos e os indicadores da perspectiva dos clientes encontram-se expostos na Figura 2.

\begin{tabular}{|l|l|}
\hline Objetivos estratégicos & Indicadores \\
\hline $\begin{array}{l}\text { Ampliar a participação no mercado brasileiro de } \\
10 \text { a } 15 \% .\end{array}$ & $\begin{array}{l}\text {-Aumento das vendas } \\
\text {-índice de vendas para novos mercados }\end{array}$ \\
\hline Reter clientes. & $\begin{array}{l}\text {-Número de clientes retidos } \\
\text {-Índice de vendas para clientes "permanentes" }\end{array}$ \\
\hline Captar novos clientes. & $\begin{array}{l}\text {-Número de novos clientes obtidos } \\
\text {-Número de novos municípios atingidos } \\
\text {-Índice de vendas para novos clientes }\end{array}$ \\
\hline Satisfazer os clientes. & $\begin{array}{l}\text {-Diminuição das reclamações } \\
\text {-Diminuição no tempo de atendimento às reclamações } \\
\text {-Pesquisa de satisfação com os clientes }\end{array}$ \\
\hline
\end{tabular}

Figura 2: Objetivos estratégicos e seus indicadores para a perspectiva dos clientes

Conforme se pode observar na Figura 2, o grande foco da empresa quanto à perspectiva dos clientes é ampliar a participação no mercado brasileiro em torno de 10 a $15 \%$. Isto se encontra diretamente relacionado à maior divulgação dos produtos atuais e ao lançamento de novos produtos, como o soro desmineralizado e o concentrado protéico, por meio do fortalecimento da sua área comercial e estruturação da equipe de vendas.

O delineamento do segmento de atuação da empresa (soro em pó, soro concentrado e creme) está bem definido, o que se apresenta como um fator positivo se analisado à luz da teoria, ou seja, dá à empresa maiores chances de rentabilidade hajam vista o foco em determinados segmentos de mercado e o maior conhecimento das necessidades de seu mercado-alvo. Nesta direção, Kaplan e Norton (1997) ressaltam que alinhar as medidas essenciais de resultados aos clientes com os segmentos de mercado é um dos fatores de grande impacto na perspectiva financeira.

No tocante a reter clientes, destacam-se a necessidade de melhoria contínua nos processos de produção e a oferta de novos produtos e serviços com custos diferenciados como fator atrativo. Para analisar o alcance deste objetivo, sugere-se que a empresa avalie o número de clientes que voltam a comprar e o volume de vendas para esses clientes.

Quanto a captar novos clientes, a empresa pretende atingi-la pela ampliação do mix dos produtos Os indicadores que se sugerem para avaliar se esse objetivo está sendo atingido são o número de novos clientes obtidos, o número de municípios abrangidos e o índice de vendas para esses novos clientes. 
Em se tratando de satisfazer clientes, a estruturação da área comercial da empresa também contribuirá para a melhoria deste objetivo, pois este setor poderá realizar um acompanhamento mais criterioso da pós-venda e dar feedback a eventuais reclamações. Para este objetivo, sugerem-se indicadores como diminuição das reclamações dos clientes, rapidez no atendimento a essas reclamações e pesquisa de satisfação com os clientes.

Na Figura 3, apresentam-se os objetivos estratégicos e os indicadores da perspectiva dos processos internos.

\begin{tabular}{|l|l|}
\hline Objetivos estratégicos & Indicadores \\
\hline Desenvolver produtos inovadores no Brasil. & $\begin{array}{l}\text {-Número de produtos inovadores criados } \\
\text {-Grau de aceitação dos novos produtos no mercado }\end{array}$ \\
\hline Melhorar a produtividade. & $\begin{array}{l}\text {-Redução da ociosidade da fábrica } \\
\text {-Redução do desperdício }\end{array}$ \\
\hline Ampliar parcerias com clientes e fornecedores. & $\begin{array}{l}\text {-Volume de soro recebido } \\
\text {-Volume de soro processado }\end{array}$ \\
\hline
\end{tabular}

Figura 3: Objetivos estratégicos e seus indicadores para a perspectiva dos processos internos

Na perspectiva de processos internos, apresentada na Figura 3, a Sooro busca a excelência operacional, o que está em consonância com o citado por Kaplan e Norton (1997) sobre procurar criar oportunidades de negócios, melhorar os processos internos e desenvolver negócios sustentáveis.

Para desenvolver produtos inovadores, a empresa está investindo na instalação de novos equipamentos e desenvolvendo novos produtos. A esse respeito, percebe-se que a pesquisa e o desenvolvimento de novos produtos podem representar uma vantagem competitiva para a empresa, pois são desenvolvidos por meio de parcerias com empresas e instituições de ensino e pesquisa, de forma que os próprios clientes auxiliam com a indicação dos padrões de produtos a serem desenvolvidos e fornecem indicações sobre quais necessidades a empresa pode suprir. Para acompanhar esse objetivo, sugerem-se os indicadores número de produtos inovadores criados e grau de aceitação destes novos produtos no mercado.

Para melhorar a produtividade, é necessário reduzir o desperdício e utilizar a capacidade produtiva da indústria em sua totalidade. Para isso, a empresa necessita investir nas parcerias com fornecedores a fim de obter maior quantidade de matéria-prima, o que, consequentemente, ampliará a produção do soro em pó, o que permitirá que atenda melhor aos seus clientes e obtenha com isso garantia da entrega do produto que, por sua vez, se refletirá em sua perspectiva financeira. Também poderá se refletir na melhoria da logística da empresa, pois esta poderá produzir mais na safra e estocar para vender na entressafra, no caso de não conseguir aumentar o recebimento de soro nesse período, impactando fortemente na sua cadeia de valor. Um item interno destacado pelo gerente de manutenção e que se encontra implícito na melhoria da produtividade é o investimento em manutenção preditiva, a qual verifica, com equipamentos adequados, se realmente é necessário trocar uma peça no momento e, com isso, reduzir custos. Neste objetivo, os indicadores podem ser redução da ociosidade da fábrica e redução do desperdício.

Já no tocante ao objetivo de ampliação das parcerias com clientes e fornecedores, além do citado quanto à captação de matéria-prima, podem-se destacar outras ações a serem desenvolvidas pela empresa, como dar continuidade às parcerias de pesquisa e de desenvolvimento, bem como às parcerias com clientes. Para este item, sugerem-se os indicadores volume de soro recebido e volume de soro processado, pois se entende que, atualmente, a maior carência da empresa é de matéria-prima, uma vez que, se a empresa conseguir aumentar o recebimento de soro, obterá vantagens financeiras, o que igualmente promoverá o fortalecimento no relacionamento com os clientes, pois terá produto a oferecer.

Os objetivos estratégicos e seus indicadores para a perspectiva de aprendizado e crescimento são exibidos na Figura 4.

No objetivo de melhorar a capacitação dos colaboradores, ressalta-se a dificuldade existente no que tange à cultura da região na qual a empresa está inserida: visão de curto prazo. Assim, as pessoas não se preocupam em melhorar sua capacitação profissional, de forma que, para atingir esse objetivo, a empresa terá de realizar um trabalho de incentivo e motivação para despertar a vontade dos colaboradores para estudarem e se qualificarem. Neste contexto, os indicadores sugeridos são ampliação do nível de escolaridade e realização de cursos de capacitação. 


\begin{tabular}{|l|l|}
\hline Objetivos estratégicos & Indicadores \\
\hline Melhorar a capacitação dos colaboradores. & $\begin{array}{l}\text {-Ampliação do nível de escolaridade } \\
\text {-Realização de cursos de capacitação }\end{array}$ \\
\hline Melhorar o desempenho dos colaboradores. & $\begin{array}{l}\text {-Melhoria da produtividade } \\
\text {-Redução dos erros do retrabalho }\end{array}$ \\
\hline $\begin{array}{l}\text { Melhorar o sistema de informações da da } \\
\text { empresa. }\end{array}$ & $\begin{array}{l}\text {-Desenvolvimento de processos de gestão da informação } \\
\text {-Diminuição dos erros provocados pela ausência no fluxo de } \\
\text { informações }\end{array}$ \\
\hline Alinhar o capital organizacional. & -Pesquisa de clima organizacional \\
\hline
\end{tabular}

Figura 4: Objetivos estratégicos e seus indicadores para a perspectiva de aprendizado e crescimento

O objetivo de melhorar o sistema de informações da empresa é um dos pontos que mais devem ser trabalhados, pois, melhorando a comunicação e divulgando as informações necessárias, os colaboradores terão maior visão e entendimento da sua parcela de contribuição para as metas que a empresa deseja atingir. A empresa já tem tomado medidas para melhorar a prontidão das informações, estruturando sua área administrativa e concentrando as informações. Contudo, ainda necessita criar um fluxo das informações para que estas cheguem aos líderes das equipes e estes, por sua vez, possam divulgá-las aos seus colaboradores. Os indicadores a fim de que este item possa ser avaliado são desenvolvimento de processos de gestão da informação e diminuição dos erros provocados pela ausência no fluxo de informações.

A respeito de alinhar o capital organizacional, percebe-se que o clima organizacional da empresa é favorável, pois a rotatividade de funcionários é pequena. No entanto, falta alinhamento devido às informações serem passadas de maneira informal e as decisões serem pouco compartilhadas. Sugerimos que este item seja avaliado por meio de pesquisa de clima organizacional.

A Sooro teve um crescimento muito rápido em poucos anos, o que fez com que surgisse a necessidade de ajustes, principalmente de melhorias relacionadas a informações e intensificação de ações visando à melhoria na capacitação dos colaboradores. Isto implica na preparação da empresa no sentido de se aperfeiçoar no que se refere ao relacionamento com os clientes a fim de atingir seu objetivo de crescimento de faturamento.

Na Figura 5, apresentam-se os objetivos estratégicos e indicadores propostos para a perspectiva do meio ambiente.

\begin{tabular}{|l|l|}
\hline Objetivos estratégicos & Indicadores \\
\hline $\begin{array}{l}\text { Aumentar eficácia na } \\
\text { utilização de recursos }\end{array}$ & $\begin{array}{l}\text {-Quantidade de lenha adquirida em relação ao volume de produção } \\
\text {-Indice de água reutilizada em relação ao volume de produção } \\
\text {-Volume de não-conformidades ambientais de fornecedores em relação ao total recebido }\end{array}$ \\
\hline $\begin{array}{l}\text { Minimizar os resíduos } \\
\text { poluentes }\end{array}$ & $\begin{array}{l}\text {-Volume de resíduos enviados para tratamento de efluentes em relação ao produzido } \\
\text {-Índices de emissão de gases ambientais em relação ao volume de produção } \\
\text {-Volume de lixo produzido em relação ao produzido }\end{array}$ \\
\hline $\begin{array}{l}\text { Ampliar o marketing } \\
\text { ambiental }\end{array}$ & $\begin{array}{l}\text {-Pesquisa de percepção com funcionários a respeito das práticas ambientais } \\
\text {-Quantidade e número de participantes de treinamento sobre práticas ambientais para } \\
\text { funcionários e comunidade } \\
\text {-Pesquisa de percepção dos clientes sobre práticas ambientais da empresa } \\
\text {-Matérias veiculadas em meios de comunicação }\end{array}$ \\
\hline
\end{tabular}

Figura 5: Objetivos estratégicos e seus indicadores para a perspectiva do meio ambiente

Quanto ao meio ambiente, entende-se que a empresa está afinada com esse tema, pois a própria matéria-prima empregada consiste em um resíduo da produção dos lácteos. O objetivo estratégico de aumentar a eficácia na utilização de recursos está relacionado com um projeto em andamento da empresa, no qual uma área foi adquirida para o reflorestamento de eucaliptos empregados como energia (lenha). No futuro, a empresa pretende se tornar autosuficiente na produção da lenha necessária para seu processo produtivo. Assim, para avaliar esse processo, a empresa pode empregar o indicativo de quantidade de lenha comprada de outros produtores em relação ao volume de produção.

A empresa também está ampliando volume de água resultante do processo produtivo que é reutilizada por meio da aquisição de um novo equipamento. Assim, pode-se reutilizar parte do volume desse recurso natural necessário para a produção, bem como o reduzir a vazão para o tratamento de efluentes e os custos com aquisição de água potável e tratamento de efluentes.

Outro aspecto importante relacionado a esse objetivo refere-se à qualidade da principal matériaprima utilizada, ou seja, o soro in natura. Se este produto chega à Sooro sem a qualidade necessária, necessita ser descartado, acarretando resíduos poluentes que necessitam ser tratados nos efluentes. Para 
avaliar a efetividade das ações de prevenção destas não-conformidades desenvolvidas pela organização, como orientação e auditoria aos fornecedores, pode-se fazer uso do indicador de volume de nãoconformidade ambiental de fornecedores em relação ao total recebido.

Percebe-se que estes dois últimos aspectos destacados (reutilização de água e prevenção de nãoconformidades na matéria-prima) também estão relacionados ao segundo objetivo estratégico desta perspectiva: minimizar os resíduos poluentes. Isso porque auxiliam na redução do volume de resíduos a ser tratados nos efluentes, impactando também nos custos. Assim, para mensuração do impacto destes processos, a empresa pode empregar o indicador de volume de resíduos enviados para tratamentos de efluentes em relação ao produzido. Outros indicadores para esse objetivo são os índices de emissão de gases e o volume de lixo produzido, ambos em relação ao volume de produção. Por meio do acompanhamento destes indicadores, a empresa pode desenvolver práticas de redução de resíduos, como troca de filtros das chaminés, reciclagem e diminuição no consumo de materiais que se tornam lixo.

Tornar a empresa conhecida e divulgar o trabalho ambiental que a mesma realiza é no que consiste o objetivo relacionado a ampliar o marketing ambiental. Para tanto, é importante a divulgação, dentro da própria empresa e para a comunidade, das práticas de produção mais limpa adotadas pela Sooro. Assim, essas pessoas podem conhecer os cuidados ambientais que a Sooro pratica, sabendo expressar o que significam esses cuidados e divulgando-os para outras pessoas. No caso dos funcionários, isto pode ser avaliado juntamente com a pesquisa de clima organizacional, trabalhando nos colaboradores o orgulho em pertencer a uma empresa que se preocupa com as questões ambientais. Outro indicativo pode ser o número de treinamentos sobre práticas ambientais e de seus participantes oferecidos para funcionários e comunidade.

Também se sugere a divulgação do respeito e do trabalho realizado pela empresa em relação ao meio ambiente, por meio de veiculações em meios de comunicação, como jornais, revistas, rádio e televisão. Ademais, a empresa poderá divulgar idéias inovadoras nessa área, tal como a reutilização da água.

Estas ações poderão impactar positivamente na perspectiva dos clientes, auxiliando na captação, satisfação e retenção de clientes. Para avaliar esse processo, pode-se, juntamente com a pesquisa de satisfação com clientes, realizar uma pesquisa sobre a percepção destes a respeito das práticas ambientais da Sooro.

Após identificar os objetivos estratégicos e propor seus indicadores, na Figura 6, apresenta-se o mapa estratégico com base no BSC proposto para a empresa analisada e aprovado pela diretoria.

O mapa estratégico proposto, apresentado na Figura 6, inclui as cinco perspectivas tradicionais do BSC - financeira, dos clientes, dos processos internos, da aprendizagem e do crescimento - e uma perspectiva que emergiu por meio da verificação empírica e da análise dos dados: a do meio ambiente.

Em relação à perspectiva meio ambiente, emergiram três objetivos principais: a) aumentar eficácia na utilização de recursos, b) minimizar os resíduos poluentes e c) marketing ambiental, sendo que os dois primeiros impactam no terceiro. Esses três objetivos impactam no aumento da participação do mercado, pois tornam a empresa competitiva devido ao cuidado com estes aspectos. Além disso, os dois primeiros objetivos impactam na redução de custos com consumo de água, tratamento de efluentes e aquisição de lenha, enquanto o terceiro pode favorecer a captação, satisfação e retenção dos clientes.

Na perspectiva do aprendizado e crescimento, os objetivos mais relevantes que emergiram foram: a) melhorar a capacitação dos colaboradores, b) melhoria no desempenho dos colaboradores, c) melhoria no sistema de informações da empresa e d) alinhamento do capital organizacional. Os três primeiros objetivos impactam no alinhamento do capital organizacional da empresa, que envolve cultura, liderança, alinhamento (metas e incentivos de acordo com a estratégia) e trabalho em equipe. Essa perspectiva como um todo impacta diretamente na melhoria da produtividade da empresa, principalmente no que tange à redução de custos. Ainda nesta perspectiva, o sistema de informações é que possibilitará a divulgação e o acompanhamento das estratégias da empresa, bem como, se necessário, o realinhamento dos objetivos e dos indicadores estratégicos.

Na perspectiva dos processos internos, os objetivos que se destacaram são: a) desenvolver produtos inovadores para o Brasil, b) melhoria da produtividade, c) ampliar parcerias com clientes e fornecedores. 0 desenvolvimento dos produtos inovadores e a ampliação nas parcerias com clientes e fornecedores impactam diretamente na ampliação da participação no mercado brasileiro. Além disso, o desenvolvimento 
de produtos inovadores impacta na ampliação do mix de produtos, assim como a melhoria da produtividade e a ampliação nas parcerias impactam na redução dos custos. Esta última relação entre ampliação nas parcerias e redução dos custos se explica pelo fato de que, por meio da ampliação do número de fornecedores e, consequentemente, do aumento da quantidade de matéria-prima processada, a empresa otimizará a capacidade produtiva existente.

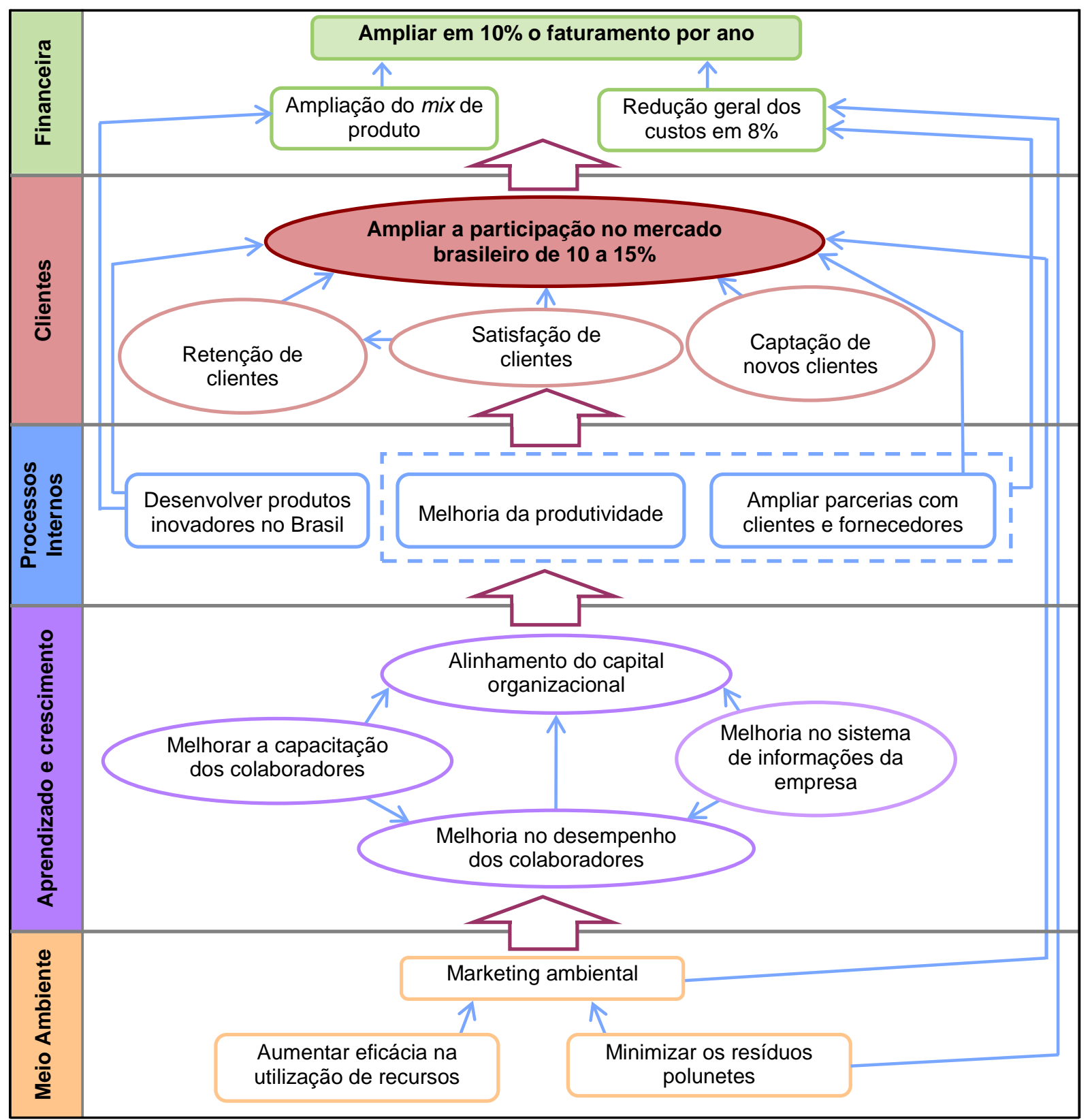

Figura 6: Mapa estratégico proposto para a empresa analisada com base no BSC

Na perspectiva dos clientes, emergiu como objetivo geral ampliar a participação no mercado brasileiro de 10 a 15\%, a ser atingido por meio dos objetivos: a) retenção de clientes, b) satisfação de clientes e c) captação de novos clientes. Estes objetivos impactarão diretamente na perspectiva financeira, ou seja, no aumento do faturamento em $10 \%$ ao ano.

Todas as perspectivas citadas impactarão na perspectiva financeira, cujo objetivo geral consiste em crescer $10 \%$ ao ano em faturamento. Para atingir este objetivo geral, a empresa também buscará a) ampliar o mix de produto e b) reduzir custos. 
A partir dos resultados apresentados, foi possível analisar os objetivos e os indicadores das cinco perspectivas analisadas, bem como a relação entre eles por meio do mapa estratégico construído com base no BSC para a empresa analisada.

\section{Considerações Finais}

Este estudo teve como principal objetivo desenvolver um mapa estratégico para uma empresa do setor de lácteos a partir de diferentes perspectivas do BSC. No decorrer da realização do estudo de caso, percebeu-se que, para a empresa analisada, integrante do setor de lácteos, além das quatro perspectivas básicas do BSC, existia uma quinta perspectiva essencial para a estratégia da organização: a do meio ambiente.

Assim, percebe-se que, hoje, a perspectiva do meio ambiente é fundamental para as empresas do setor analisado, vista a crescente pressão de leis ambientais e do mercado consumidor no tocante ao cuidado com o meio ambiente. Isto se deve ao fato de as empresas deste setor gerarem grande quantidade de resíduos poluentes em decorrência de seu processo produtivo, além do consumo de energia e de água, das emissões atmosféricas e dos ruídos e/ou vibrações. Especificamente sobre a empresa pesquisada, destaca-se que a própria matéria-prima empregada consiste em um resíduo poluente gerado por outras indústrias.

A partir do exposto, foi possível propor a inclusão da perspectiva do meio ambiente para o mapa estratégico da empresa analisada, bem como elaborar, como contribuição teórica do estudo, medidas que podem ser empregadas por empresas do setor lácteo para incluir essa perspectiva ao empregarem o BSC.

O desenvolvimento do mapa estratégico para a empresa, a partir do BSC, demonstrou que todas as perspectivas analisadas causam impacto sobre a perspectiva financeira, em relação a qual o principal objetivo da organização é ampliar em $10 \%$ o faturamento por ano.

As análises permitiram observar, também, que a empresa possui alguns desafios a enfrentar, como ampliar a captação de matéria-prima para otimizar seu processo produtivo e melhorar o sistema de informação existente. Outro aspecto que merece destaque é a tendência da empresa em realizar parcerias, tanto para a secagem do soro quanto para a realização de pesquisas, o que, de acordo com Kaplan e Norton (1997), contribui para a melhoria dos processos e para a inovação.

No sentido apontado, a empresa procura inovar constantemente em equipamentos e produtos, além de ser pioneira no Brasil no tocante ao trabalho com o soro de leite, o que demonstra sua forte característica inovadora e corrobora o apontado por Kaplan e Norton (1997) de que o processo de inovação é considerado uma forma de criação de valor pelas quais as empresas buscam a identificação e o cultivo de novos clientes e mercados e as necessidades emergentes de seus clientes atuais, para, a partir daí, lançarem novos produtos e serviços que possibilitem o alcance de novos mercados e clientes, além de satisfazer os já existentes.

Além do exposto, de acordo com Nascimento (1997), atualmente se considera que as empresas que dispõem de inovação tecnológica podem preservar mais o meio ambiente, o que pode ser observado na empresa analisada no tocante, por exemplo, à aquisição de um equipamento para tornar potável a água resultante do processo produtivo.

Como implicação gerencial, destaca-se que a criação de um mapa estratégico para a empresa pesquisada, ainda não existente nesta, pode contribuir para seu gerenciamento estratégico, visto que possibilita a definição de objetivos para a empresa e a proposição de indicadores para mensurar o alcance desses objetivos abrangendo outras perspectivas além da financeira. Neste sentido, como destacam Kaplan e Norton (1997), os objetivos e as medidas do BSC surgem da visão e da estratégia da empresa, traduzindo a missão e a estratégia de uma unidade de negócios em objetivos e em medidas tangíveis.

A inclusão da perspectiva do meio ambiente e a proposição de medidas para empresas do setor de lácteos podem contribuir para a empresa analisada, assim como para outras do setor, visto o acirramento da legislação e a fiscalização de órgãos governamentais, bem como a pressão do mercado consumidor no que tange a esse cuidado com o meio ambiente.

A partir dos resultados encontrados, sugere-se à empresa pesquisada que invista na obtenção de matéria-prima, para otimizar seu processo produtivo, e na melhoria de seu sistema de informação, para proporcionar a divulgação e o alinhamento das suas estratégias entre todos os seus setores e integrantes. 
Como limitação desta pesquisa, destaca-se que os resultados obtidos não podem ser generalizados para outros casos e períodos de tempo. Para futuras pesquisas, sugere-se a realização de outros estudos em empresas de lácteos ou ampliar as medidas propostas neste estudo para a perspectiva do meio ambiente. Também se recomenda a realização de outras pesquisas sobre a ampliação das perspectivas do BSC, conforme características da empresa analisada e seu ramo de atividade.

\section{Notas}

1- Os autores agradecem aos avaliadores da Revista RECADM por suas contribuições ao estudo.

\section{Referências}

Bardin, L. (2002). Análise de conteúdo. Lisboa: Edições 70.

Berber, S. J. N., Ribeiro, J. L. D. \& Kliemann Neto, F. J. (2006). Análise das causas do fracasso em implantações de BSC. Revista Produção Online, Florianópolis, 6(2), p. 1-22.

Brasil. (2009). Lei n. 10.165, de 27 de dezembro de 2000. Instituto Brasileiro do Meio Ambiente e dos Recursos Naturais Renováveis. Disponível em: <http://servicos.ibama.gov.br/ctf/manual/html/040100.htm>. Acesso em: 06 fev.

Brasil. (2009). Resolução n. 313, de 29 de outubro de 2002. Conselho Nacional do Meio Ambiente, Disponível em: <www.mma.gov.br/port/conama/res/res02/res31302.html>. Acesso em: $06 \mathrm{fev}$.

Carvalho, F. M., Dias, L. N. S., \& Prochnik, V. (2005). A utilização do Balanced Scorecard em hospitais: o caso do Hospital Nove de Julho. Anais do Congresso Internacional de Custos, Florianópolis, SC, Brasil, 9.

Fontes, E. A. N. (2004). O alinhamento estratégico e a construção do futuro com o Balanced Scorecard. 130f. Dissertação (Mestrado em Administração) - Centro de Ciências Sociais Aplicadas, Universidade Federal do Rio de Janeiro, Rio de Janeiro, 2004.

Gil, A. C. (2004). Métodos e técnicas de pesquisa social. 5. ed. São Paulo: Atlas, 1999.

Godoy, A. S. (1995, mai./jun) Pesquisa qualitativa: tipos fundamentais. Revista de Administração de Empresas, São Paulo, 35(3), p. 20-29.

Goldszmidt, R. G. B., \& Profeta, R. A. (2004). Implementação da estratégia: um estudo de casos comparativo ao arcabouço conceitual do Balanced Scorecard. Anais do Simpósio de Administração de Produção, Logística e Operações Internacionais, São Paulo, SP, Brasil, 07.

Kaplan, R. S., \& Norton, D. P. (1997). A estratégia em ação: Balanced Scorecard. Rio de Janeiro: Campus, 1997.

Kaplan, R. S., \& Norton, D. P. (1999). Using the Balanced Scorecard as a strategic management system. Boston: Harward Business Review.

Maganha, M. F. B. (2006). Guia técnico ambiental da indústria de produtos lácteos. São Paulo: CETESB.

Paraná. (2009). Resolução n. 028, de 17 de agosto de 1998. Secretaria de Estado de Meio Ambiente e Recursos Hídricos. Disponível em: <http://www.iap.pr.gov.br/../meioambiente/arquivos/File/iap/resol_028_98.pdf>.Acesso em: 06 fev. 2009.

Paraná. (2009). Resolução n. 054, de 2006. Secretaria do Estado do Meio Ambiente e Recursos Hídricos SEMA. Disponível em: <http://www.iap.pr.gov.br/arquivos/File/meioambiente/res_054_06.pdf> Acesso em: 30 mai. 2009.

Paraná. (2009). Resolução n. 054, de 22 de dezembro de 2006. Secretaria de Estado de Meio Ambiente e Recursos Hídricos. Disponível em: <www.emiatec.com.br/pdf/res_054_06.pdf>. Acesso em: 06 fev. 2009.

Pessanha, D. (2004). Obstáculos à implementação do Balanced Scorecard: estudos de casos em empresas brasileiras. 2004. Dissertação (Mestrado em Ciências Contábeis) - Centro de Ciências Sociais Aplicadas, Universidade Federal do Rio de Janeiro, Rio de Janeiro: FACC/UFRJ, 2004.

Prieto, V., Pereira, F., Carvalho, M., \& Laurindo, F. (2006, jan./abr.). Fatores críticos na implantação do Balanced Scorecard. Revista Gestão \& Produção, 13(1), p. 81-92.

Soares Júnior, H., \& Prochnik, V. (2004). Experiências comparadas de implantação do Balanced Scorecard no Brasil. Anais do Congresso Latino Americano de Estratégia, Santa Catarina, Brasil, 17.

Sousa, C. R., \& Bertolin, Ro. V. (2008). Representações Sociais Naturalistas na Gestão Ambiental: o delineamento de uma Aprendizagem Organizacional Fragmentada e Instrucional. Anais do Encontro de Estudos Organizacionais, Belo Horizonte, MG, 05. 
Stake, R. E. (2005). Investigación con estudio de casos. Madrid: Sage Publications.

Yin, R. K. (2005). Estudo de caso: planejamento e métodos. Porto Alegre: Bookman. 